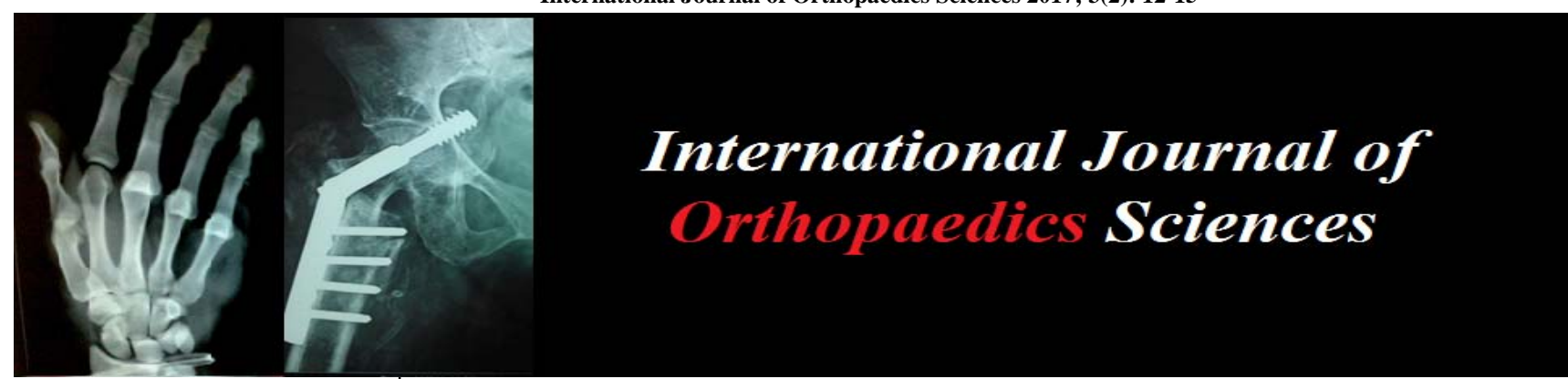

ISSN: 2395-1958

IJOS 2017; 3(2): 12-15

(C) 2017 IJOS

www.orthopaper.com

Received: 03-02-2017

Accepted: 04-03-2017

Dr. Aurobinda Das

Assistant professor, Department of Orthopaedics, Hitech Medical College and Hospital,

Bhubaneswar, Odisha, India

Dr. Saswat Samant

Junior Resident, Department of Orthopaedics, Hitech Medical College and Hospital,

Bhubaneswar, Odisha, India

Dr. Pragyan Dash

Junior Resident, VSS Medical College and Hospital. Burla,

Odisha, India
Correspondence Dr. Aurobinda Das

Assistant professor, Department of Orthopaedics, Hitech Medical College and Hospital,

Bhubaneswar, Odisha, India

\section{A comparison study of preoperative skin preparation using chlorhexidine vs povidone iodine in cases of elective orthopaedic surgery}

\section{Dr. Aurobinda Das, Dr. Saswat Samant and Dr. Pragyan Dash}

DOI: http://dx.doi.org/10.22271/ortho.2017.v3.i2a.03

Abstract

Preoperative skin preparation is an inalienable part of the patient preparation in any orthopaedic surgery. The obvious goal of this step is to reduce the possibility of a postoperative wound infection. Unfortunately, guidelines/recommendations to achieve these goals are still to be universally agreed upon. The aim of the study was to determine a preferred method for preoperative skin preparation in clean surgeries for closed fractures. We compared the postoperative infection rates in 120 orthopaedic cases managed with elective surgery, which had undergone preoperative skin preparation with either chlorhexidine or povidone iodine. The effect of each method of skin preparation was studied. Results were analyzed statistically The overall rate of surgical site infection was considerably lower in the chlorhexidine group $(12.3 \%)$ than in the povidone iodine group $(6.66 \%, \mathrm{p}=0.008)$, while the cost of the antiseptics wasn't different. This study demonstrates that antisepsis with chlorhexidine and was associated with a significant reduction in the rate of SSIs compared to povidone-iodine antisepsis. Hence, Chlorhexidine antiseptics should be the preferred choice for preoperative skin preparation in elective cases of orthopaedic surgery.

Keywords: Preoperative, skin preparation, orthopaedics, povidone iodine, chlorhexidine

\section{Introduction}

Preoperative skin preparation is an inalienable part of the patient preparation in any orthopaedic surgery. As skin is a major source of pathogens, it is obvious that improving skin antisepsis would decrease surgical-site infections ${ }^{[1,2]}$. The obvious goal of this step is to reduce the possibility of a postoperative wound infection. Unfortunately, guidelines/recommendations to achieve these goals are still to be universally agreed upon. A study previously done on foot and ankle surgery patients demonstrated a better reduction of bacterial contamination with chlorhexidine in alcohol ${ }^{[5]}$. Chlorhexidine has also been demonstrated to be more effective than povidone-iodine for skin preparation in decreasing bacterial colony counts in the operative fields in vaginal hysterectomy cases ${ }^{[6]}$, in reducing surgical site infection in patients undergoing elective gynecological laparotomies ${ }^{[9]}$, as well as reducing bloodstream infections in patients with central vascular lines for insertion site disinfection ${ }^{[7]}$. However, there has not been a comparative study between chlorhexidine and povidone iodine antiseptic skin preparations for overall use in elective cases of orthopaedic surgery. Our objective was to compare povidone iodine with chlorhexidine in preoperative skin preparation in cases of elective orthopaedic surgeries and determine whether one of them was more effective than the other.

2. Material and methods: This study was conducted on 420 orthopaedic cases which were managed with elective surgery between august 2014 to July 2016 at four centers including one tertiary care center. All the cases had undergone preoperative skin preparation with either chlorhexidine or povidone iodine.

The inclusion criteria were males and females of 18-75 years of age, cases of elective orthopaedic surgery, ASA class 1 and $2^{[14]}$ and a duration of surgery within the range of 30 minutes to 3 hours. 
The exclusion criteria was the patient's refusal to participate in the study, open fractures of any grade, associated contaminated wounds, evidence of any infection at or adjacent to the operative site, uncontrolled diabetes, immunosuppressed state, allergy to any of the study agents, a duration of surgery exceeding 3 hours or under 30 minutes and inability to follow up the patient for 3 weeks post op.

Out of the 420 patients included in the study, the patients were included in one of the two groups. Both groups were standardized with inclusion and exclusion criteria and similar standard guidelines. Two types of preoperative skin antiseptics were considered. Group 1 patients was patients were initially scrubbed for 5 minutes with povidone iodine scrub (Povidone-Iodine Solution IP 7.5\% w/v) solution which was followed with a povidone iodine paint (Figure 1) while group 2 patients were scrubbed with chlorhexidine (Chlorhexidine Gluconate Solution IP 4\% w/v) for 5 minutes which was followed by chlorhexidine paint (Figure 2). Patients in both the groups had received standard prophylaxis against possible infection that included preoperative intravenous antibiotics. Hair removal was done with an epilation cream in all the cases. All other factors including draping, preoperative antibiotic administration and method of hair removal were kept constant in all the cases. Thereby leaving preoperative skin preparation with antiseptics as the only variable. We followed the CDC guidelines which state that: the size of the area prepared should be sufficient to include any potential incision sites divorced from the main incision site; the solution should be applied in concentric circles; a dedicated instrument may be used; This applicator should be discarded once the periphery has been reached and time should be allowed for the solution to dry ${ }^{[16]}$.

Next, the surgical wounds were examined on the 2nd postoperative day (during dressing) and then on 6th postoperative day. This was followed by an examination of the wound during stitch removal on postoperative day 12 and 1 week later i.e. on 18 th postoperative day. A surgical site infection was diagnosed as per the criteria underlined by the US CDC ${ }^{[11]}$. Whenever surgical-site infection was diagnosed clinically, samples were sent for gram staining, culture, and

sensitivity. The patient's adverse condition was studied by an investigator who was unaware of the group that had been assigned to the patient. All data collected were entered into the spreadsheet. Data analysis was done.

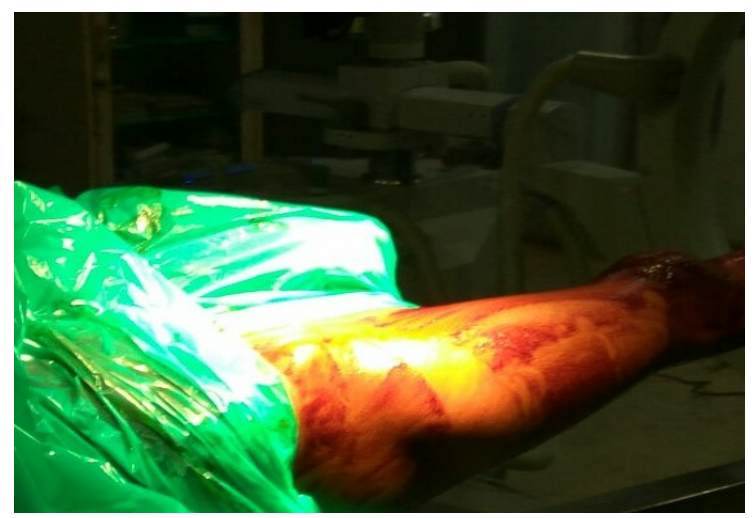

Fig 1: Surgical area scrubbed and painted with povidone iodine.

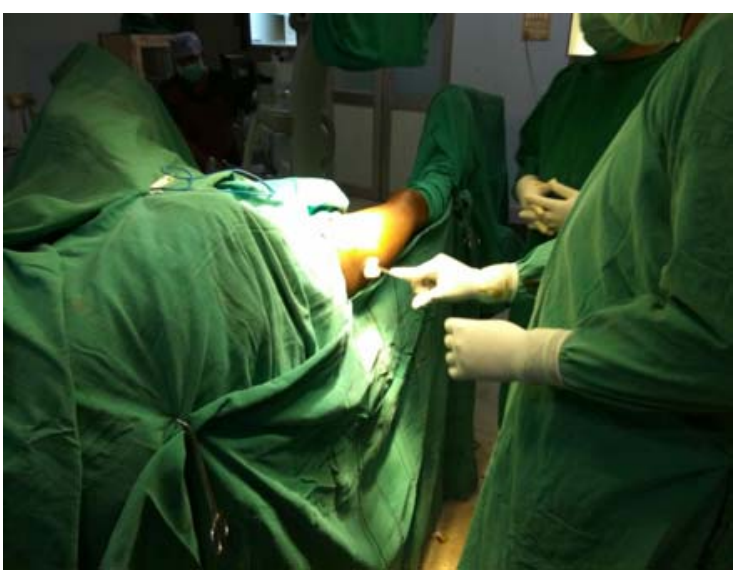

Fig 2: Surgical area scrubbed and painted with chlorhexidine.

\section{Results}

Table 1: Details of patients about $(\mathrm{N}=420)$

\begin{tabular}{|c|c|c|c|}
\hline \multicolumn{2}{|c|}{} & Group-1(N-210) (Povidone iodine ) & Group-2(N-210) (Chlorhexidine) \\
\hline \multicolumn{2}{|c|}{ Mean Age (SD) } & 48 & 50 \\
\hline \multirow{2}{*}{ Gender } & Male & 116 & 122 \\
\cline { 2 - 4 } & Female & 94 & 88 \\
\hline \multicolumn{2}{|c|}{ Operative time } & 1.55 & 1.50 \\
\hline
\end{tabular}

Table 2: Postoperative surgical wound infection

\begin{tabular}{|c|c|c|c|}
\hline & Group 1 & Group 2 & Relative Risk \\
\hline Postoperative infection [no. (\%)] & $26(12.3 \%)$ & $14(6.66 \%)$ & 0.5385 \\
\hline
\end{tabular}

Relative risks are for chlorhexidine group as compared with povidone-iodine group. The $95 \%$ confidence intervals were calculated

Relative risk

0.5385

$95 \%$ CI 0.2894 to

1.0019

z statistic

1.954

Significance levelP $=\quad 0.0507$

NNT (Benefit) $\quad 17.500$

95\% CI 8.848 (Benefit) to 792.706 (Benefit)
Table 3: Analysis of incidence of infection

\begin{tabular}{|c|c|c|c|}
\hline & A & B & Total \\
\hline Infected & 26 & 14 & 40 \\
\hline Non infected & 184 & 196 & 380 \\
\hline Total & 210 & 210 & 420 \\
\hline
\end{tabular}

Our primary outcome was any surgical site infection within 3 weeks of surgery. A secondary outcome was the cost of the pre-op scrub and paint applied during the skin preparation.

420 patients who underwent elective orthopaedic surgery were studied prospectively. The patients were in 2 groups of 210 each. The preoperative skin preparation of patients in 
group 1 was with the povidone iodine scrub and paint while group 2 had been prepared with chlorhexidine scrub and paint.

There was no statistical difference of the risk factors between the two groups in terms of age, operative time and gender.

There were 26 cases of surgical site infection in group 1 compared to only 14 cases in group 2 . The overall rate of surgical site infection was considerably lower in the chlorhexidine group $(12.3 \%)$ than in the povidone iodine group $(6.66 \%, \mathrm{p}=0.008)$.

There were 5 cases of allergic reaction in the povidone iodine group while there was no such incidence in the chlorhexidine group.

\section{Discussion}

Although the WHO states that "there is no single, objective gold standard test for surgical wound infection", majority follow either the US CDC criteria or the European ECDC guidelines ${ }^{[12]}$ to define surgical site infection. Since the patient's skin can contribute as an important source of pathogens that cause surgical site infection, optimization of preoperative skin antisepsis may decrease postoperative infections ${ }^{[10]}$. Hence the removal of bacteria and commensals has been advocated by The Royal College of Surgeons of England as well as the CDC ${ }^{[16]}$.

In elective orthopaedic surgeries the development of surgical site infections can broadly be considered due to bacterial contamination during the surgery, the duration of the procedure, or underlying diseases such as immune deficiency, diabetes, and malnutrition etc (which would predispose the patient to an infection) ${ }^{[1]}$. The Centers for Disease Control and Prevention (CDC) recommends that patients shower or bathe with an antiseptic solution the night before surgery and that the skin is prepared with "an appropriate antiseptic agent." [3] Guidelines from the National Institute for Health and Clinical Excellence recommend that patients shower or bathe with soap the day before or on the day of surgery. Even here there is no recommendation favoring chlorhexidine or povidone iodine ${ }^{[3,4]}$.

In their study on antiseptic skin preparation for general surgery patients, Paocharoen $\mathrm{V}$ et al showed that chlorhexidine significantly reduced colonization of bacteria and the incidence of postoperative wound infection ${ }^{[8]}$. Veiga et al reached almost the same conclusion that chlorhexidine is a better agent for use as a skin antisepsis before elective clean plastic surgery procedures ${ }^{[15]}$.

A comprehensive review by Dumville et al found some evidence that preoperative skin preparation with chlorhexidine was associated with lower rates of SSIs following clean surgery than povidone iodine paint ${ }^{[16]}$. In our study, we controlled the risk factors like underlying diseases and the duration of the orthopaedic surgery. We standardized both groups with inclusion and exclusion criteria. The risk factor that we did not control was the preoperative skin preparation protocol.

After analysis, we found that there was no significant statistical difference based on age, operative time and gender (Table 1). The SSI rate was $12.3 \%$ in the povidone iodine group and $6.66 \%$ in the chlorhexidine group.

Colour staining and hypersensitivity are other disadvantages of using povidone iodine. Five of the patients (without a known history of allergy to povidone iodine showed an allergic reaction to the pre-op skin preparation). No such hypersensitivity was reported in the chlorhexidine group.

\section{Conclusion}

The financial and social burden of surgical site infections is considerable ${ }^{[16]}$.

The results from the statistical analysis of this study revealed that the rate of surgical site infection was significantly less in the chlorhexidine group as compared to the povidone-iodine group, while the cost wasn't significantly different. Hence chlorhexidine antiseptics should be the preferred choice for preoperative skin preparation in elective cases of orthopaedic surgery.

\section{References}

1. Dunn DL, Beilman GJ. Surgical infections. In: Brunicardi FC, Andersen DK, Billiar TR, Dunn DL, Hunter JG, Matthews JB, et al, editors. Schwartz's principles of surgery. 8th ed. New York: McGraw-Hill, 2005, 109-28.

2. Napolitano LM. Decolonization of the skin of the patient and surgeon. Surg Infect (Larchmt) 2006; 7(3):S3-S15.

3. National Collaborating Centre for Women's and Children's Health. Surgical Site Infection: Prevention and Treatment of Surgical Site Infection. London: National Institute for Health and Clinical Excellence, 2008. http://www.nice.org.uk/nicemedia/live/11743/42378/423 78.pdf.

4. Kamel C, McGahan L, Polisena J, Mierzwinski-Urban M, Embil J. Preoperative Skin Antiseptic Preparations for Preventing Surgical Site Infections: A Systematic Review. Infection Control \& Hospital Epidemiology. 2012; 33(06):608-617.

5. Bibbo C, Patel DV, Gehrmann RM, Lin SS. Chlorhexidine provides superior skin decontamination in foot and ankle surgery: a prospective randomized study. Clin Orthop Relat Res. 2005; 438:204-8.

6. Culligan PJ, Kubik K, Murphy M, Blackwell L, Snyder J. A randomized trial that compared povidone iodine and chlorhexidine as antiseptics for vaginal hysterectomy. Am J Obstet Gynecol. 2005; 192:422-5.

7. Chaiyakunapruk N, Veenstra DL, Lipsky BA, Saint S. Chlorhexidine compared with povidone iodine solution for vascular catheter-site care: a meta-analysis. Ann Intern Med. 2002; 136:792-801.

8. Paocharoen V, Mingmalairak C, Apisarnthanarak A. Comparison of Surgical Wound Infection after Preoperative. [Internet]. J Med Assoc Thai. [cited 2017Feb24]. Available from: http://www.mat.or.th/journal. J Med Assoc Thai. 2009; 92(7):898-902

9. Levin I, Amer-Alshiek J, Avni A, Lessing J, Satel A, Almog B. Chlorhexidine and Alcohol Versus PovidoneIodine for Antisepsis in Gynecological Surgery. Journal of Women's Health. 2011; 20(3):321-324.

10. Chlorhexidine-Alcohol versus Povidone-Iodine for Surgical-Site Antisepsis. Darouiche RO, Wall MJ Jr, Itani KM, et al. N Engl J Med. 2010; 362(1):18-26. The Spine Journal. 2010; 10(5):457.

11. CDC - Table 1: SSI Guideline, 1999 - HICPAC [Internet]. Cdc.gov. 2017 [cited 25 February 2017]. Available from: https://www.cdc.gov/hicpac/SSI/table1SSI.html

12. Global guidelines on the prevention of surgical site infection [Internet]. World Health Organization. 2017 [cited 25 February 2017]. Available from: http://www.who.int/gpsc/ssi-prevention-guidelines/en/

13. Vagholkar K, Julka K. Preoperative Skin Preparation: 
Which Is The Best Method? The Internet Journal of Surgery. 2012; 28(4).

14. American Society of Anesthesiologists - ASA Physical Status Classification System [Internet]. Asahq.org. 2017 [cited 28 February 2017]. Available from: https://www.asahq.org/resources/clinicalinformation/asa-physical-status-classification-system

15. Veiga D, Damasceno C, Veiga-Filho J, Figueiras R, Vieira R, Florenzano $\mathrm{F}$ et al. Povidone Iodine versus Chlorhexidine in Skin Antisepsis before Elective Plastic Surgery Procedures: A Randomized Controlled Trial. Plastic and Reconstructive Surgery. 2008; 122(5):170e$171 \mathrm{e}$.

16. Dumville J, McFarlane E, Edwards P, Lipp A, Holmes A, Liu Z. Preoperative skin antiseptics for preventing surgical wound infections after clean surgery. 2017. 